\title{
Behavioural responses of fish groups exposed to a predatory threat under elevated $\mathrm{CO}_{2}$
}

1

2 Cattano $\mathrm{C}^{1,2}$, Fine $\mathrm{M}^{3,4}$, Quattrocchi $\mathrm{F}^{5}$, Holzman $\mathrm{R}^{4,6}$, Milazzo $\mathrm{M}^{1,2}$

3

4

5

6

Citation: Cattano C., Fine M., Quattrocchi F., Holzman R., Milazzo M., 2019. Behavioural responses of fish groups exposed to a predatory threat under elevated CO2. Marine Environmental Research. 147: 179-184. https://doi.org/10.1016/j.marenvres.2019.04.011

URL: https://www.sciencedirect.com/science/article/pii/S0141113619300546?via\%3Dihub

\section{Supplemental material:}

https://www.sciencedirect.com/science/article/pii/S0141113619300546?via\%3Dihub\#appsec1

\footnotetext{
${ }^{1}$ Dipartimento di Scienze della Terra e del Mare (DiSTeM), Università di Palermo, Via Archirafi 20, I-90123 Palermo, Italy. C. Cattano: carlo.cattano@unipa.it

${ }^{2}$ CoNISMa, Piazzale Flaminio 9, 00197 Roma. Italy

${ }^{3}$ The Mina and Everard Goodman Faculty of Life Sciences, Bar-Ilan University, Ramat-Gan 52900, Israel

${ }^{4}$ The Interuniversity Institute for Marine Sciences, Eilat 88103, Israel

${ }^{5}$ Institute for marine biological resources and biotechnologies. Via Vaccara, 61 - 91026 Mazara del Vallo (TP), Italy

${ }^{6}$ Department of Zoology, The George S. Wise Faculty of Life Sciences, Tel Aviv University, Tel Aviv, Israel
}

\section{Abstract}

0 Most of the studies dealing with the effects of ocean acidification (OA) on fish behaviour tested individuals in isolation, even when examining species that school. Here we evaluated the effects of elevated $\mathrm{CO}_{2}$ concentrations (i.e. $\sim 900 \mu \mathrm{atm}$ ) on the shelter use and group cohesion of the gregarious damselfish Chromis viridis using groups of sub-adults exposed to a predatory threat. Results showed that, under predatory threat, fish reared at elevated $\mathrm{CO}_{2}$ concentrations displayed a risky behaviour (i.e. decreased shelter use), whereas their group cohesion was unaffected. Our findings add on increasing 


\section{Author Generated Postprint}

evidence to account for social dynamics in OA experiments, as living in groups may compensate for $\mathrm{CO}_{2}$-induced risky behaviour. boldness.

Keywords: Coral reef fish; group fish; Ocean Acidification; predation; shelter use; global change; risk assessment

\section{Introduction}

Oceans mitigate the effects of anthropogenic activities on the global climate by absorbing about a third of the atmospheric $\mathrm{CO}_{2}$. However, this occurs at costs of changing physical and chemical seawater conditions (Doney et al., 2009). Increasing dissolved $\mathrm{CO}_{2}$ concentration in seawater leads to carbonate chemistry changes and $\mathrm{pH}$ drop, a process known as Ocean Acidification (OA). Projections suggest that ocean partial pressure of $\mathrm{CO}_{2}\left(p \mathrm{CO}_{2}\right)$ could approximate to average $1000 \mu$ atm and $\mathrm{pH}$ will further drop by 0.3 units by the end of the century (Meinshausen et al., 2011).

During the last decade several experiments showed that fish reared at elevated $p \mathrm{CO}_{2}$ levels display behavioural disruptions, including altered responses to visual, olfactory and auditory stimuli, reduced learning ability, increased boldness (i.e. the propensity to be explorative and to take risks) and decreased lateralization (reviewed in Nagelkerken \& Munday, 2016; Cattano et al., 2018). Such observed disruptions may negatively affect ecological processes, like settlement and habitat selection (e.g. Devine \& Munday, 2013; Rossi et al., 2015), foraging (e.g. Ferrari et al., 2012), predation avoidance (e.g. Ferrari et al., 2011a) and reproduction (Milazzo et al., 2016). The underlying mechanisms altered under OA are linked to impairments of the olfactory system and to the disruption of the GABAa receptor function, as a result of changes in ion gradients with acid base regulation under elevated $\mathrm{CO}_{2}$ conditions (Nilsson et al., 2012; Heuer et al., 2016; Porteus et al., 2018; Williams et al., 2018). This evidence provides important insights on how OA might influence future responses of fish at the population level (Munday et al., 


\section{Author Generated Postprint}

49

50

51

52

53

54

55

56

57

2013a; Sunday et al., 2014; Lefevre, 2016). Despite this, other studies documented no effects of rising $\mathrm{CO}_{2}$ on fish behaviour (e.g., Cattano et al., 2017; Jutfelt \& Hedgärde, 2015; Sundin et al., 2017), suggesting that fish sensitivity to OA may be species-specific (Ferrari et al., 2011a ), as well as being dependent upon the ecological context in which the experiments are conducted (e.g. Goldenberg et al., 2018).

To date, most of the assessments of $\mathrm{CO}_{2}$-mediated effects on fish behaviour were carried out on isolated individuals, whilst whether and how OA conditions may affect behavioural responses of fish in group has only recently received attention (Lopes et al., 2016; Nadler et al., 2016a; Kwan et al., 2017; Maulvault et al., 2018). Group living occurs in the majority of animal taxa (Krause \& Ruxton, 2002) and confers a number of benefits for individuals such as improved foraging opportunities, energy use, predator detection and predator avoidance (Pitcher \& Parrish, 1993). More cohesive groups reduce the probability of predation through an enhanced "confusion effect" (Neill \& Cullen 1974) and an improved ability for preys to detect a threat (Magurran et al., 1985). Some disrupted behaviours under elevated $\mathrm{CO}_{2}$, such as lateralization, boldness, escape response, cue recognition and risk assessment, are known to play a key role in fish group cohesion and social interaction dynamics (Bisazza \& Dadda, 2005; Ward \& Currie, 2013; Seebacher \& Kraise, 2017). Therefore, we can expect that under OA conditions, social behaviour and group formation could be affected potentially leading to negative consequences for the benefits of living in group. On the other hand, laboratory experiments suggest that living in a group may improve the physiological performance (Nadler et al., 2016b), the escape response (Domenici, 2010) and may reduce the cost of locomotion (Marras et al., 2015) of the individuals. Since the performance of an individual in isolation does not necessarily reflect the response of the same individual within a group (Domenici \& Batty, 1997; Domenici, 2010; Semeniuk \& Dill, 2005) it is essential to understand whether the behavioural alterations observed on single-individual experiments under OA conditions may occur 


\section{Author Generated Postprint}

72 also when multi-individual fish groups face with elevated $\mathrm{CO}_{2}$ conditions (Kwan et al., 2017; Nadler et

73

74

al., 2016a).

In this study, we used fish groups to evaluate the effects of elevated $p \mathrm{CO}_{2}$ levels predicted for the end of this century (i.e. $900 \mu \mathrm{atm}$ ) on anti-predator responses of a gregarious coral-reef species. In particular, we aimed to test the hypothesis that elevated $\mathrm{CO}_{2}$ concentrations affect the shelter use and the response to a food stimulus (both as proxies of boldness), along with the cohesion of fish groups exposed or not to a predatory threat. To this end, we used the blue-green damselfish Chromis viridis, a widespread IndoPacific planktivore fish forming groups above branching corals where they find shelter (Lecchini et al., 2005).

\section{Material and Methods}

\subsection{Fish maintenance and $\mathrm{CO}_{2}$ treatment}

The experiment was carried out in the Red Sea Simulator (RSS) at the Interuniversity Institute for Marine Sciences (IUI, Eilat, Israel). The RSS is an open, flow-through aquaria system capable of manipulating environmental parameters, such as seawater temperature and $\mathrm{pH}$ (Bellworthy \& Fine, 2018). A pH probe (SeaFET, Satlantic, Halifax, Canada) reports pH of nearby reef water to the system and the set value of the $\mathrm{pH}$ in the aquarium is a delta from the reef $\mathrm{pH}$ value. A two-armed robot, equipped with temperature (PT100), dissolved oxygen (VisiFerm DO ARC 120, Hamilton, Switzerland) and pH (POLILYTE PLUS ARC 120, Hamilton, Switzerland) probes on each arm, monitor each aquarium. In addition, each aquarium is equipped with permanent probes used to feedback the $\mathrm{pH}$ and temperature control. Total alkalinity (TA) in the aquaria was daily measured with titration until the day before the experiment $(\mathrm{n}=$ 4; Compact Titrosampler, Metrohm AG, Herisau, Switzerland). Dissolved inorganic carbon (DIC), $\Omega_{\mathrm{arag}}$, $\mathrm{HCO}_{3}{ }^{-}, \mathrm{CO}_{3}{ }^{2-}, \mathrm{CO}_{2(\mathrm{aq})}$ and $p \mathrm{CO}_{2}$ values were calculated from the $\mathrm{pH}_{\mathrm{NBS}}$ and $\mathrm{TA}$ measurements using the 


\section{Author Generated Postprint}

95

96

97

98

99

Table 1. Summary of seawater carbonate chemistry variables recorded in the rearing tanks for Control and High

$\mathrm{CO}_{2}$ conditions. Salinity did not vary and was set at the average value of $40.7 \%$ o for subsequent calculations.

Temperature and $\mathrm{pH}$ data were averaged daily $(\mathrm{n}=4)$. Total Alkalinity $(\mathrm{TA})$ was assessed on discrete water samples $(n=4)$. Data are reported as mean $( \pm$ S.E. $)$.

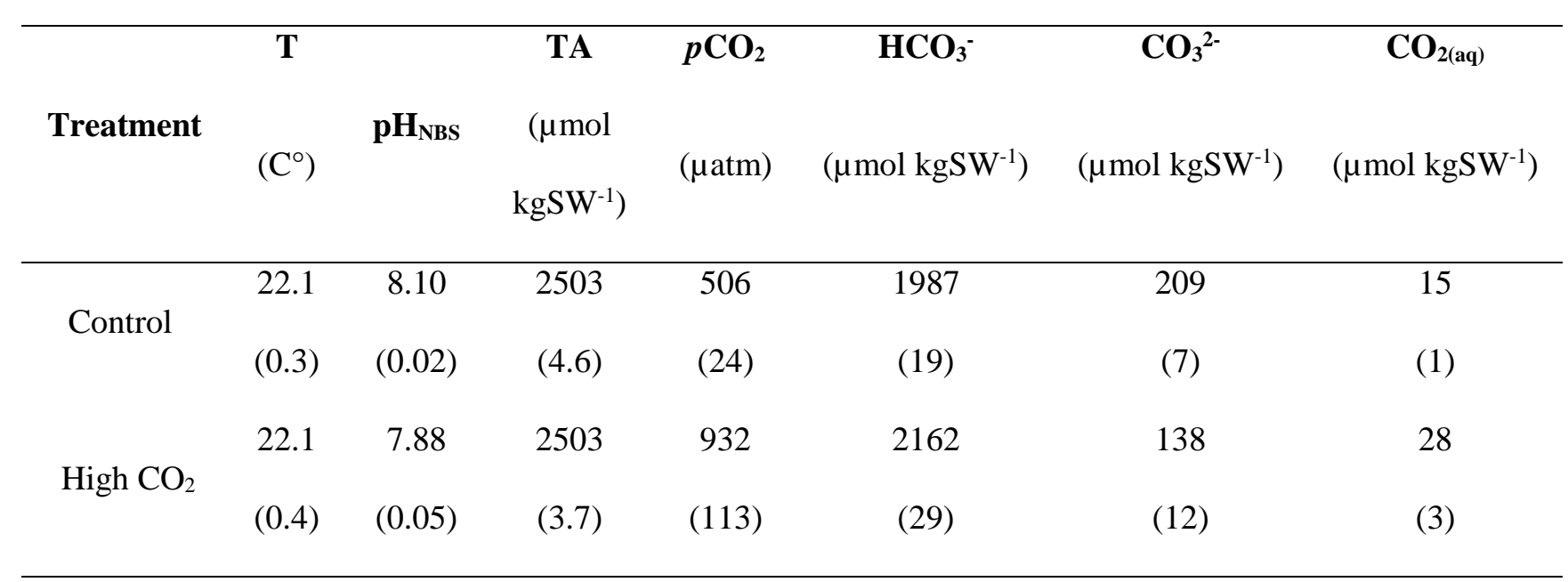

100

101 In April 2016, C. viridis sub-adults were collected by hand nets from the shallow reefs off the north-west 102

103

104

105

106

107

program $\mathrm{CO}_{2}$ SYS.xls (Pierrot \& Wallace, 2006). The selected $\mathrm{K}_{1}$ and $\mathrm{K}_{2}$ carbonic acid dissociation constants were according to Mehrbach et al. (1973) as refit by Dickson \& Millero (1987) and $\mathrm{KSO}_{4}$ as determined by Dickson (1990). Seawater carbonate chemistry variables in Control and High $\mathrm{CO}_{2}$ treatments are reported in Table 1. side of the Gulf of Aqaba $\left(29^{\circ} 30^{\prime} 16.9^{\prime \prime} \mathrm{N} 34^{\circ} 55^{\prime} 07.4^{\prime \prime E}\right)$. Fish were transferred to the RSS where they were housed in $35 \mathrm{~L}$ aquaria at temperature conditions matching field conditions (daily average $\sim 23^{\circ} \mathrm{C}$ ). Successively, the two $\mathrm{CO}_{2}$ conditions (Control and High $p \mathrm{CO}_{2}$; Table 1) were randomly assigned to four different $35 \mathrm{~L}$ rearing tanks (the two High $\mathrm{CO}_{2}$ tanks were independently dosed; dimensions of each tank: L: 40 x W: 25 x H: $35 \mathrm{~cm}$; fish density within each tank: 4.3 individuals $1^{-1}$; water flow 351 per hour). Before running the experimental test, fish were reared at Control and $\mathrm{High} \mathrm{CO}_{2}$ conditions for five days, 


\section{Author Generated Postprint}

108

109

110

111

112

113

114

115

116

117

118

119

120

121

122

123

124

125

126

127

128

129

130

which is a sufficient exposure time to observe OA-induced behavioural effects (Munday et al., 2010). Fish were daily fed with Artemia adults and nauplii, and food withheld for 12 hours before testing. Maintaining diel variability is the default setting in the RRS, hence seawater $\mathrm{pH}$ is not fixed at a certain level, but rather as a delta from incoming ambient reef water conditions (Bellworthy \& Fine, 2018). During the exposure period, we recorded a daily $p \mathrm{CO}_{2}$ variation of $\sim 230 \mu$ atm (S.D.) in the High $\mathrm{CO}_{2}$ condition (Table 1).

\subsection{Experimental setup}

Following the 5-days $\mathrm{CO}_{2}$ exposure, the behaviour of C. viridis groups was assessed in three different $25 \mathrm{~L}$ tanks (see Fig. S1 for a schematic representation of the experimental arenas). Each tank was equipped with continuous water flow (1 1 per hour) and subdivided in half by a vertical rigid mesh (1 $\mathrm{mm}$ mesh size) that allowed for water movement between the two sides of the tank. One side of each experimental tank hosted a group of $C$. viridis sub-adults and was equipped with an Acropora sp. (Scleractinia, Hexacoralia) colony, used as a shelter (surface: $44-48 \mathrm{~cm}^{2}$ ). The other tank side hosted the predator Epinephelus fasciatus or remained empty in the No-predator treatment. Each tank was surrounded on four sides by black plastic to avoid any other visual stimulus, which could potentially influence the damselfish behaviour.

\subsection{Experiment and fish behaviour assessment}

A group of three randomly chosen $C$. viridis individuals at a time from each $\mathrm{CO}_{2}$ condition was transferred to one of the experimental tanks for each treatment (i.e. Predator and No-predator treatments). A total of 34 groups were used during the experiment (n: Control $\mathrm{CO}_{2} /$ Predator $=8$, Control $\mathrm{CO}_{2} / \mathrm{No}-$ predator $=10, \mathrm{High} \mathrm{CO}_{2} /$ Predator $=9, \mathrm{High} \mathrm{CO}_{2} / \mathrm{No}$-predator $=7$ ). Each group of three damselfish subadults constituted an independent sample and was used only one time. For each trial, $C$. viridis individuals were habituated to the experimental arena for 15 minutes. This time period was preliminary assessed as 


\section{Author Generated Postprint}

131 being sufficient for fish to leave the shelter and have a regular swimming behaviour. After this

132 acclimation time, the behaviour of $C$. viridis group was recorded for 5 minutes using a digital video 133 camera (GoPro Hero 3+) located above the tank. The videos were successively analyzed to obtain every

1345 seconds the position of each fish and assess the fish group centroid. Then, the following variables were 135 recorded: 1) sheltering time (percent time spent inside the shelter), calculated as the number of frames in 136 which the fish group centroid was into the shelter out the total number of analyzed frames. 2) Distance 137 from the Shelter, which is the mean distance $(\mathrm{cm})$ of the fish group centroid from the shelter. 3) Inter138 Individual Distance (IDD), which is a measure of the distance among the individuals calculated as the 139 mean distance of each fish (center of mass) to all other group mates when the whole group was outside 140 the coral (Kwan et al., 2017). At the end of the 5-minute observation, each fish group was approached 141 with a plastic pipette to make fish take shelter into the coral. Then, a fixed amount of Artemia sp. adults 142 was introduced in the experimental tank close to the dividing mesh using the same pipette (5 ml), and 143 the time interval (s) each individual took to emerge from the shelter (TES) and reach the food was 144 recorded during one additional minute. Total length (TL, $\mathrm{cm}$ ) of each fish used in the experiment was 145 obtained from video frames using ImageJ software (http://rsb.info.nih.gov/ij/). Fish individuals were 146 measured when at the bottom of the tanks using a scale bar as a reference.

147 To ensure identical $\mathrm{CO}_{2}$ exposure duration, the entire experiment was carried out on a single day (from

1488 a.m. to 6 p.m.). All fish were tested under control $\mathrm{CO}_{2}$ water conditions, as recent evidence showed 149 that experimental test water does not change high $\mathrm{CO}_{2}$-induced behavioural effects (Munday et al., 2016). 150 The experiment complied with IACUC approved guidelines for the use and care of animals in research 151 at Bar-Ilan University, Israel.

$152 \quad 2.4$ Data analyses 


\section{Author Generated Postprint}

153 Potential differences in experimental fish body size were tested by a two-way ANOVA $\left(\mathrm{CO}_{2}\right.$ treatment,

1542 levels: Control and High; Predator, 2 levels: Presence, Absence). In order to analyze the shelter use

155 (sheltering time and distance from the shelter), the group cohesion (IDD), and time to emerge from the

156 shelter' (TES), three different analyses were used. Sheltering time was analyzed using a general linear

157 model (GLM) with a binomial distribution, as the data were assessed as a proportion. The significance

158 of treatments and their interaction were tested by the sequential likelihood ratio test (LR). To test the

159 significance of $\mathrm{CO}_{2}$ and Predator effects on the distance from the shelter and on the average distance

160 among individuals (IID), the analysis of variance based on resampling ( $\mathrm{n}=999)$ was used to overcome

161 the unbalanced design issue (Warton et al., 2016), and was performed using the 'mvabund' package as

162 above. The effects of $\mathrm{CO}_{2}$ and Predator factors, along with their interaction, on TES were analyzed using

163 a negative binomial GLM with log link function accounting for data overdispersion (Zuur et al., 2007).

164 The LR test was used to test the significance of the treatments and their interaction under the null

165 hypothesis of no association between these and the TES. Post-hoc analyses were performed for those

166 models in which the interaction term was significant by the use of the 'lsmeans' (Lenth, 2016) and

167 'multcomp' packages (Hothorn et al., 2008). All the analyses were performed using the R software 168 version 3.3.0 (R Core Team, 2016).

\section{Results}

Total length of fish used for the experiment $(\mathrm{n}=102)$ did not significantly differ between $\mathrm{CO}_{2}$ treatments [mean TL: 2.89 ( \pm 0.03 S.E.) $\mathrm{cm}$ and 2.95 ( \pm 0.04 S.E.) $\mathrm{cm}$ in in Control and $\mathrm{High} \mathrm{CO}_{2}$ condition, respectively; ANOVA: $\left.\mathrm{F}_{1,98}=1.01, \mathrm{p}>0.05\right)$ ]. High $p \mathrm{CO}_{2}$ levels did not affect the time spent inside the shelter ("sheltering time") by $C$. viridis sub-adults in the absence of the predator. However, when the predator was present, fish reared at high $\mathrm{CO}_{2}$ concentrations spent $80 \%$ less time inside the shelter than

175 fish exposed to Control $\mathrm{CO}_{2}$ condition (Fig. 1a; $\mathrm{CO}_{2}$ x Predator: $\mathrm{LR}=74.245$, $\mathrm{p}<0.001$; Table S1). On 


\section{Author Generated Postprint}

176 average, in the absence of the predator, the fish groups from $\mathrm{High} \mathrm{CO}_{2}$ condition displayed a distance

177 from the shelter slightly higher $(+7 \%)$ than the control fish groups (Fig. 1b). This difference resulted

178 more evident when fish were exposed to the predator threat, with fish groups from high $\mathrm{CO}_{2}$ venturing

$179 \sim 30 \%$ farther from the shelter than control fish (Fig. 1b). Therefore, the distance from the shelter was

180 significantly different for $\mathrm{CO}_{2}$ and Predator factors separately $\left(\mathrm{CO}_{2}: \mathrm{F}=5.439, \mathrm{p}<0.05\right.$; Predator: $\mathrm{F}=5.708$,

$181 \mathrm{p}<0.05)$, but not for their interaction (Table S2).

182 Fish displayed similar group cohesion, in all $\mathrm{CO}_{2}$ and predator treatments. However, the inter-individual 183 distance (IID) significantly decreased (i.e. increased group cohesion) in presence of the predator in both $184 \mathrm{CO}_{2}$ conditions (Figure 1c; $\mathrm{CO}_{2}: \mathrm{F}=0.519, \mathrm{p}>0.05$; Predator: $\mathrm{F}=6.305, \mathrm{p}<0.05$; Table $\mathrm{S} 4$ ).

185 In the absence of the predator, when the food was introduced in the experimental arena, fish from both $186 \mathrm{CO}_{2}$ conditions took a similar time to emerge from the shelter (i.e. TES; Fig. 1d), whilst under predatory 187 threat fish from the High $\mathrm{CO}_{2}$ condition emerged almost 5 times faster from the shelter than those from 188 Control condition (Figure 1d; $\mathrm{CO}_{2} \times$ Predator: $\mathrm{LR}=6.70, \mathrm{p}<0.01$; Table S5). 


\section{Author Generated Postprint}
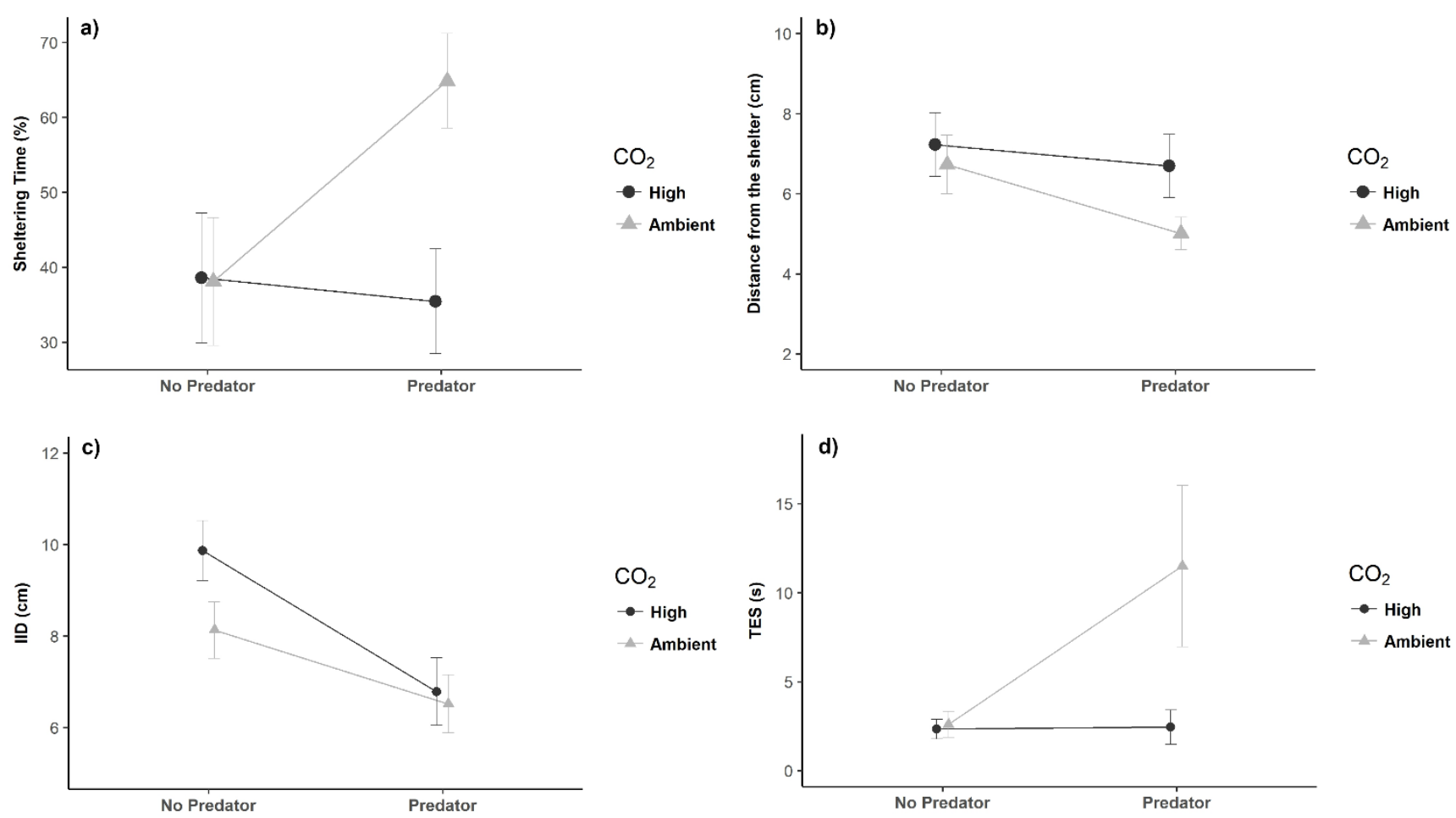

Figure $1-\mathrm{CO}_{2}$ effects on the a) mean ( \pm S.E.) sheltering time (time spent inside the shelter), b) distance from the shelter, c) Inter-Individual Distance (IID) among fish and d) time to emerge from the shelter (TES) displayed by groups of $C$. viridis sub-adults in presence/absence of their predator.

See table S1-S4 for full statistical results and pair wise contrasts. Sample size for the independent individual groups tested was: $\mathrm{n}=10$ for Control/No-predator treatment; $\mathrm{n}=7$ for High $\mathrm{CO}_{2} / \mathrm{No}_{\text {-predator; }}$ $\mathrm{n}=8$ for Control/Predator treatment and $\mathrm{n}=9$ for High $\mathrm{CO}_{2} /$ Predator treatment.

\section{Discussion}

Here we show that short-term exposure to elevated $\mathrm{CO}_{2}$ concentrations did not affect the shelter use, the time to reach the food and the group cohesion in $C$. viridis sub-adults, but instead led to increased boldness and risky behaviour in presence of a predatory threat. Indeed, fish groups from high $\mathrm{CO}_{2}$ condition exposed to a predator almost doubled the time spent outside the shelter, ventured on average $30 \%$ farther from the branching coral and responded to the food stimulus almost 5 times faster than fish groups reared at control condition. When fish face with a threatening situation, they typically exhibit 


\section{Author Generated Postprint}

204

205

206

207

208

209

210

211

212

213

214

215

216

217

218

219

220

221

222

223

224

225

226

227

some behavioural responses to minimize the risk of predation, such as increased sheltering, decreased feeding and activity levels (Lima \& Dill, 1990; Ferrari et al., 2010). Elevated $\mathrm{CO}_{2}$ concentrations affect such anti-predator responses altering threat perception through sensorial and neurological impairments. As a result, threat-exposed fish display riskier behaviours under OA conditions than under ambient $\mathrm{CO}_{2}$ concentrations. In this regard, our findings are consistent with previous studies showing that acute exposure to elevated $p \mathrm{CO}_{2}$ levels affects the innate ability of fish to recognize a predatory threat, leading to increased boldness (Lönnsted et al., 2013; Munday et al., 2010, 2012, 2013b).

We documented damselfishes under high $\mathrm{CO}_{2}$ condition did not change their response to the food stimulus either in the presence or in the absence of the predator. By contrast, fish reared at control $\mathrm{CO}_{2}$ water remained close to the shelter and reached the food five-fold slower than in the absence of the predator, hence displaying a typical behavioural change in response to the predatory threat. Similarly, a recent experiment showed that juveniles of Amphiprion percula reared at elevated $\mathrm{CO}_{2}$ conditions did not change their feeding activity in presence of a predator cue, displaying a riskier behaviour under predatory threat than fish reared at ambient $\mathrm{CO}_{2}$ conditions, regardless of food resources availability (McMahon et al., 2018). Our findings support the evidence that threat perception is impaired under OA conditions (Ferrari et al., 2012; Chivers et al., 2014). Such behavioural disruption makes prey more vulnerable to predation, potentially affecting population dynamics of many species (Munday et al., 2010; Ferrari et al., 2011a, b). However, experimental evidence showed that an increased prey vulnerability to predation may disappear when both predators and prey are concomitantly exposed to high $\mathrm{CO}_{2}$ conditions (Allan et al., 2013), suggesting that the extent to which predator-prey dynamics will be affected under OA conditions will depend upon differences in tolerance of the interacting species and upon their adaptation ability. In addition to this, recent evidence suggested that diel variation of $p \mathrm{CO}_{2}$ levels might reduce the severity of behavioral alterations caused by elevated $\mathrm{CO}_{2}$. For instance, the negative effects on lateralization and predator cue recognition observed in two coral reef species exposed to elevated 


\section{Author Generated Postprint}

228

229

230

231

232

233

234

235

236

237

238

239

240

241

242

243

244

245

246

247

248

249

250

stable $\mathrm{CO}_{2}$ conditions $(\sim 1000 \mu \mathrm{atm})$ were mitigated when using fluctuating $p \mathrm{CO}_{2}$ levels during acclimation (Jarrold et al. 2017). In the present study fish were exposed to diel $\mathrm{CO}_{2}$ fluctuation, therefore we expect the detrimental behavioural effects we observed on $C$. viridis under OA conditions could be more severe under stable elevated $\mathrm{CO}_{2}$ conditions.

If in one hand becoming bolder might increase the risk for fish of being preyed, on the other a bolder behaviour could increase the time spent in foraging activity leading to enhanced growth rate and increased body size. This in turn may decrease mortality due to predation, as capture success would decline with increasing prey length (e.g. Miller et al., 1988). Therefore, we suggest OA may affect the species trade-off between predation avoidance and food obtaining, which greatly relies on risk perception (McMahon et al., 2018; Nagelkerken \& Munday, 2016).

Our results also documented no differences in the group cohesion (measured as the average distance among individuals of each group) displayed by damselfish sub-adults from different $\mathrm{CO}_{2}$ conditions. Such finding is consistent with a recent study showing that neither constant nor oscillating $\mathrm{CO}_{2}$ affected the inter-individual distance in shoals of Chromis punctipinnis juveniles (Kwan et al., 2017). By contrast, other recent evidence reported negative $\mathrm{CO}_{2}$-induced effects on shoaling behaviour of Argyrosomus regius juveniles (Maulvault et al., 2018). Lopes et al., (2016) showed that Atherina presbyter larvae exposed for 7 days to elevated $\mathrm{CO}_{2}$ displayed decreased shoal cohesion, but this effect was reversed after a 21-day exposure. These studies suggest that effects on group cohesion may be temporary and contextdependent, changing with species, habitat or ontogenetic stage.

Contrary to our expectations, OA levels did not affect $C$. viridis group cohesion, which was higher in the presence than in the absence of the predator. Under a predatory threat, preys typically increase group cohesion (Sogard \& Olla, 1997). Indeed, both group living and group cohesion may represent an important anti-predator strategy improving threat detection, reducing individual risk and enhancing 


\section{Author Generated Postprint}

251 acquisition of information by preys (Pitcher \& Parrish, 1993). High cohesive groups display increased

252 ability of detecting a threat (Ward et al., 2011) and are less sensitive to predation through an enhanced

253 “confusion effect” (Neill \& Cullen, 1974). Moreover, groups confer a number of additional benefits to

254 individuals, such as greater foraging success (Pitcher \& Parrish, 1993) and reduced physiological costs

255 associated to swimming (e.g. Marras et al., 2015). Very likely, our results suggests that exhibiting a high

256 group cohesion under OA may compensate the risk associated with a bolder behaviour displayed in

257 presence of the predator. In summary, here we show that sub-adults of a widespread tropical damselfish

258 do alter their perception of predatory threat when exposed to short-term elevated $\mathrm{CO}_{2}$, whereas the group

259 cohesion seems to be unaffected. The bold behaviour displayed by $\mathrm{CO}_{2}$-treated fish in the presence of a

260 predator threat could lead to increased mortality, with potential consequences for population

261 replenishment (Munday et al., 2010; Ferrari et al. 2011b). On the other hand, fish could benefit from a

262 bold behaviour spending more time in feeding-related activities than shy fish under a predatory risk,

263 hence potentially increasing their size and altering their vulnerability to predation (Miller et al., 1998).

264 This study also emphasizes the importance of the social context when assessing the responses of

265 gregarious fish species to environmental disturbances.

266 An additional intriguing result of our experiment is that when the predator was not present we did not detect any OA-induced effects on fish group boldness (sheltering time, shelter distance and TES between the $\mathrm{CO}_{2}$ conditions). This finding suggests that the extent to which fish responses are affected under elevated $\mathrm{CO}_{2}$ may depend on the ecological context in which the experiment is conducted (Goldenberg et al., 2018). Similarly, some recent wild-based evidence reported that scaling up responses of single species experiments to multi-species interactions (e.g. predator vs prey) may change the ecological outcome under OA conditions (Nagelkerken et al., 2017). We recognize some limitations of the present study, as we were not able to compare the anti-predator behaviour displayed by multi-individual groups 


\section{Author Generated Postprint}

275 stressors condition (e.g. with concomitant changes in $\mathrm{O}_{2}$ availability and temperature), as well as cannot

276 exclude transgenerational acclimation to $\mathrm{CO}_{2}$ effects (e.g. Munday 2014). In conclusion, our results

277 advocate the need to increase the number of studies dealing with $\mathrm{CO}_{2}$ effects on chronically exposed 278 group-living fish along natural $\mathrm{CO}_{2}$ gradients. Indeed, field investigations could better reflect the 279 complexity of organism's interactions, their adaptation to natural variability in $\mathrm{pH}$ and $p \mathrm{CO}_{2}$, and may 280 further explain the role of acclimation and adaptation processes in a context of a changing ocean.

282 Acknowledgments

283 The authors would like to thank Dror Komet and the IUI staff for the technical assistance. This paper is 284 part of the Ph.D. dissertation of CC and was funded by an additional training grant provided by the 285 University of Palermo (Italy) to carry out research in a foreign lab.

286 The Red Sea Simulator was funded in part by an Israel Science Foundation grant to MF.

References

1. Allan, B.J., Domenici, P., McCormick, M.I., Watson, S.A., \& Munday, P.L., (2013) 8(3), e 58520

2. Bellworthy, J., Fine, M., (2018) The Red Sea Simulator: A high-precision climate change mesocosm with automated monitoring for the long-term study of coral reef organisms. Limnology and Oceanography: Methods 16, 367-375

3. Bisazza, A., Dadda M., (2005) Enhanced schooling performance in lateralized fishes. 


\section{Author Generated Postprint}

297

298

299

300

301

302

303

304

305

306

307

308

309

310

311

312

313

314

315

316

317

4. Cattano, C., Calò, A., Di Franco, A., Firmamento, R., Quattrocchi, F., Sdiri, K., Guidetti, P., Milazzo, M., (2017) Ocean acidification does not impair predator recognition but increases juvenile growth in a temperate wrasse off $\mathrm{CO}_{2}$ seeps. Marine Environmental Research 132, $33-40$

5. Cattano, C., Claudet, J., Domenici, P., Milazzo, M., (2018) Living in a high $\mathrm{CO}_{2}$ world: a global meta- analysis shows multiple trait-mediated fish responses to ocean acidification. Ecological Monographs, 1-16

6. Chivers, D.P., McCormick, M.I., Nilsson, G.E., Munday, P.L., Watson, S.A., Meekan, M.G., Mitchell, M.D., Corkill, K.C., Ferrari, M.C., (2014) Impaired learning of predators and lower prey survival under elevated $\mathrm{CO}_{2}$ : a consequence of neurotransmitter interference. Global Change Biology, 20(2), 515-522

7. Devine, B.M., Munday, P.L., (2013) Habitat preferences of coral-associated fishes are altered by short-term exposure to elevated $\mathrm{CO}_{2}$. Marine Biology, 160(8), 1955-1962

8. Dickson, A.G. (1990) Standard potential of the reaction: $\mathrm{AgCl}(\mathrm{s})+12 \mathrm{H} 2(\mathrm{~g})=\mathrm{Ag}(\mathrm{s})+\mathrm{HCl}(\mathrm{aq})$, and the standard acidity constant of the ion $\mathrm{HSO}_{4}{ }^{-}$in synthetic sea water from 273.15 to 318.15 K. The Journal of Chemical Thermodynamics 22, 113-127

9. Dickson, A.G., Millero, F.J., (1987) A comparison of the equilibrium constants for the dissociation of carbonic acid in seawater media. Deep-Sea Research Part I: Oceanographic Research Papers 34, 1733-1743

10. Domenici P., Batty R.S., (1997) Escape behaviour of solitary herring (Clupea harengus) and comparisons with schooling individuals. Marine Biology, 128, 29-38 


\section{Author Generated Postprint}

11. Doney, S.C., Fabry, V.J., Feely, R.A., Kleypas, J.A., (2009). Ocean acidification: the other $\mathrm{CO}_{2}$ problem. Annual Review of Marine Science 1, 169-192

12. Ferrari, M.C.O., Wisenden, B.D., Chivers, D.P., (2010) Chemical ecology of predator-prey interactions in aquatic ecosystems: a review and prospectus. Canadian Journal of Zoology, 88, 698-724.

13. Ferrari, M.C.O., Dixson, D.L., Munday, P.L., McCormick, M.I., Meekan, M.G., Sih, A., Chivers, D.P. (2011a) Intrageneric variation in antipredator responses of coral reef fishes affected by ocean acidification: implications for climate change projections on marine communities. Global Change Biology, 17, 2980-6

14. Ferrari, M.C.O., McCormick, M.I., Munday, P.L., Meekan, M.G., Dixson, D.L., Lönnstedt, O., Chivers, D.P., (2011b) Putting prey and predator into the $\mathrm{CO}_{2}$ equation - qualitative and quantitative effects of ocean acidification on predator-prey interactions. Ecology Letters, 14, $1143-1148$

15. Ferrari, M.C., McCormick, M.I., Munday, P.L., Meekan, M.G., Dixson, D.L., Lönnstedt, O., Chivers, D.P., (2012) Effects of ocean acidification on visual risk assessment in coral reef fishes. Functional Ecology, 26(3), 553-558.

16. Goldenberg, S.U., Nagelkerken, I., Marangon, E., Bonnet, A., Ferreira, C.M., Connell, S.D., (2018) Ecological complexity buffers the impacts of future climate on marine consumers. Nature Climate Change, 8(3), 229.

17. Heuer, R.M., Grosell, M., (2014) Physiological impacts of elevated carbon dioxide and ocean acidification on fish. American Journal of Physiology. Regulatory, Integrative and Comparative Physiology 307, 1061-1084 


\section{Author Generated Postprint}

18. Heuer R. M., Welch, M. J., Rummer J. L., Munday P. L., Grosell M., (2016) Altered brain ion gradients following compensation for elevated $\mathrm{CO}_{2}$ are linked to behavioural alterations in a coral reef fish. Scientific Reports 6, 33216 doi:10.1038/srep33216

19. Hothorn, T., Bretz, F., Westfall, P., (2008) Simultaneous Inference in General Parametric Models. Biometrical Journal 50(3), 346-363

20. Jarrold, M.D., Humphrey, C., McCormick, M.I., Munday, P.L., (2017) Diel $\mathrm{CO}_{2}$ cycles reduce severity of behavioural abnormalities in coral reef fish under ocean acidification. Scientific Reports, 7(1), 10153

21. Jutfelt, F., Hedgärde, M., (2015) Juvenile Atlantic cod behavior appears robust to nearfuture $\mathrm{CO}_{2}$ levels. Frontiers in Zoology 12(1), 11

22. Krause, J., Ruxton G.D., (2002) Living in groups. Oxford, UK: Oxford University Press

23. Kwan, G.T., Hamilton, T.J., Tresguerres, M., (2017) $\mathrm{CO}_{2}$-induced ocean acidification does not affect individual or group behaviour in a temperate damselfish. Royal Society Open Science 4, 170283. http://dx.doi.org/10.1098/rsos.170283

24. Lecchini, D., Shima, J., Banaigs, B., Galzin, R., (2005) Larval sensory abilities and mechanisms of habitat selection of a coral reef fish during settlement. Oecologia 143, 326334

25. Lefevre, S. (2016) Are global warming and ocean acidification conspiring against marine ectotherms? A meta-analysis of the respiratory effects of elevated temperature, high $\mathrm{CO}_{2}$ and their interaction. Conservation Physiology, 4(1), cow009

26. Lenth, R.V., (2016) Least-Squares Means: The R Package lsmeans. Journal of Statistical Software 69(1), 1-33. doi:10.18637/jss.v069.i01 


\section{Author Generated Postprint}

362

363

364

365

366

367

368

369

370

371

372

373

374

375

376

377

378

379

380

381

382

383

27. Lima, S.L., Dill, L.M., (1990) Behavioral decisions made under the risk of predation: a review and prospectus. Canadian journal of zoology, 68(4), 619-640

28. Lönnstedt, O.M., Munday, P.L., McCormick, M.I., Ferrari, M.C., Chivers, D.P., (2013) Ocean acidification and responses to predators: can sensory redundancy reduce the apparent impacts of elevated $\mathrm{CO}_{2}$ on fish?. Ecology and Evolution, 3(10), 3565-3575.

29. Lopes, A.F., Morais, P., Pimentel, M., Rosa, R., Munday, P.L., Gonçalves, E.J., Faria, A.M., (2016) Behavioural lateralization and shoaling cohesion of fish larvae altered under ocean acidification. Marine Biology 163, 1-10

30. Marras, S., Killen, S.S., Lindström, J., McKenzie, D.J., Steffensen, J.F., Domenici, P., (2015) Fish swimming in schools save energy regardless of their spatial position. Behavioural Ecology and Sociobiology, 69, 219-226.

31. Maulvault, A.L., Santos, L.H., Paula, J.R., Camacho, C., Pissarra, V., Fogaça, F., Barbosa, V., Alves, R., Ferreira, P.P., Barceló, D., Rodriguez-Mozaz, S., Marques, A., Diniz, M., Rosa, R., (2018) Differential behavioural responses to venlafaxine exposure route, warming and acidification in juvenile fish (Argyrosomus regius). Science of The Total Environment, 634, 1136-1147

32. McMahon, S.J., Donelson, J.M., Munday, P.L., (2018) Food ration does not influence the effect of elevated $\mathrm{CO}_{2}$ on antipredator behaviour of a reef fish. Marine Ecology Progress Series 586, 155-165.

33. Mehrbach, C., Culberson, C.H., Hawley, J.E., Pytkowicx, R.M., (1973) Measurement of the apparent dissociation constants of carbonic acid in seawater at atmospheric pressure.

Limnology and Oceanography 18(6), 897-907 


\section{Author Generated Postprint}

384

385

386

387

388

389

390

391

392

393

394

395

396

397

398

399

400

401

402

403

404

34. Meinshausen, M., Smith, S.J., Calvin, K., Daniel, J.S., Kainuma, M.L.T., Lamarque, J-F., Matsumoto, K., Montzka, S.A., Raper, S.C.B., Riahi, K. et al., (2011) The RCP greenhouse gas concentrations and their extensions from 1765 to 2300. Climatic Change 109, 213-241

35. Milazzo, M., Cattano, C., Alonzo, S. H., Foggo, A., Gristina, M., Rodolfo-Metalpa, R., Sinopoli, M., Spatafora, D., Stiver, K.A., Hall-Spencer, J. M., (2016) Ocean acidification affects fish spawning but not paternity at $\mathrm{CO}_{2}$ seeps. Proceedings of the Royal Society B: Biological Sciences, 283(1835), 20161021

36. Miller, T.J., Crowder, L.B., Rice, J.A., Marschall, E.A., (1988) Larval size and recruitment mechanisms in fishes: toward a conceptual framework. Canadian Journal of Fisheries and Aquatic Sciences, 45(9), 1657-1670

37. Munday, P.L., Dixson, D.L., McCormick, M.I., Meekan, M., Ferrari, M.C.O., Chivers, D.P., Karl, D., (2010) Replenishment of fish populations is threatened by ocean acidification. Proceedings of the National Academy of Sciences USA 107, 12930-12934

38. Munday, P.L., McCormick, M.I., Meekan, M.G., Dixson, D.L., Watson, S., Ferrari, M.C.O., Chivers, D.P., (2012) Selective mortality associated with variation on $\mathrm{CO}_{2}$ tolerance in a marine fish. Ocean Acidification 1, 1-5

39. Munday, P.L., Warner, R.R., Monro, K., Pandolfi, J.M., Marshall D.J., (2013a) Predicting evolutionary responses to climate change in the sea. Ecology Letters, 16, 1488-1500

40. Munday, P.L., Pratchett, M.S., Dixson, D.L., Donelson, J.M., Endo, G.G.K., Reynolds, A.D., Knuckey, R., (2013b) Elevated $\mathrm{CO}_{2}$ affects the behavior of an ecologically and economically important coral reef fish. Marine Biology, 160, 2137-2144 


\section{Author Generated Postprint}

405

406

407

408

409

410

411

412

413

414

415

416

417

418

419

420

421

422

423

424

425

426

41. Munday, P.L., (2014) Transgenerational acclimation of fishes to climate change and ocean acidification. F1000prime reports, 6

42. Munday P.L., Welch M.J., Allan B.J.M., Watson S-A., McMahon S.J., McCormick M.I., (2016) Effects of elevated $\mathrm{CO}_{2}$ on predator avoidance behaviour by reef fishes is not altered by experimental test water. Peer $J, 4$, e2501

43. Nadler, L.E., Killen, S.S., Mccormick, M.I., Watson, S., Munday, P.L., (2016a) Effect of elevated carbon dioxide on shoal familiarity and metabolism in a coral reef fish.

Conservation Physiology 4, 1-13

44. Nadler, L.E., Killen, S.S., McClure, E.C., Munday, P.L., McCormick, M.I., (2016b)

Shoaling reduces metabolic rate in a gregarious coral reef fish species. Journal of Experimental Biology, 219, 2802-2805

45. Nagelkerken, I., Munday, P.L., (2016) Animal behaviour shapes the ecological effects of ocean acidification and warming: Moving from individual to community-level responses. Global Change Biology 22, 974-989

46. Nagelkerken, I., Goldenberg, S.U., Ferreira, C.M., Russell, B.D., Connell, S.D., (2017) Species interactions drive fish biodiversity loss in a high-CO2 world. Current Biology, 27(14), 2177-2184

47. Neill, S., Cullen, J.M., (1974) Experiments on whether schooling by their prey affects the hunting behaviour of cephalopods and fish predators. Journal of Zoology, 172(4), 549-569

48. Nilsson, G.E., Dixson, D.L., Domenici, P., McCormick, M.I., Sørensen, C., Watson, S-A., Munday, P.L., (2012) Near-future carbon dioxide levels alter fish behaviour by interfering with neurotransmitter function. Nature Climate Change 2, 201-204 


\section{Author Generated Postprint}

427

49. Pierrot, D.E., Wallace, D.W.R., (2006) MS Excel program developed for $\mathrm{CO}_{2}$ system calculations. ORNL/CDIAC-105a. Carbon Dioxide Information Analysis Center, Oak Ridge National Laboratory, U.S. Department of Energy, Oak Ridge, Tennessee

50. Pitcher, T.J., Parrish, J.K., (1993) Functions of shoaling behaviour in teleosts. In Behaviour of teleost fishes (Pitcher T.J. ed), pp. 363-439. London: Chapman \& Hall

51. Porteus, C.S., Hubbard, P.C., Webster, T.M.U., van Aerle, R., Canário, A.V., Santos, E.M., Wilson, R.W., (2018) Near-future $\mathrm{CO}_{2}$ levels impair the olfactory system of a marine fish. Nature Climate Change, $\mathbf{8}(8), 737$

52. R Core Team. (2016) R: A language and environment for statistical computing. R Foundation for Statistical Computing, Vienna, Austria. http://www.R-project.org/

53. Rossi, T., Nagelkerken, I., Simpson, S.D., Pistevos, J.C.A., Watson, S-A., Merillet, L., Fraser, P., Munday, P.L., Connell, S.D., (2015) Ocean acidification boosts larval fish development but reduces the window of opportunity for successful settlement. Proceedings of the Royal Society B: Biological Sciences, 282, 20151954

54. Seebacher, F., Krause, J., (2017) Physiological mechanisms underlying animal social behaviour. Philosophical Transactions of the Royal Society B, 372, 20160231.

55. Semeniuk, C.A.D., Dill, L.M., (2005) Cost/benefit analysis of group and solitary resting in the cowtail stingray, Pastinachus sephen. Behavioral Ecology, 16, 417-426

56. Sogard, S.M., Olla, B.L., (1997) The influence of hunger and predation risk on group cohesion in a pelagic fish, walleye pollock Theragra chalcogramma. Environmental Biology of Fishes, 50(4), 405-413 


\section{Author Generated Postprint}

57. Sunday, J.M., Calosi, P., Dupont, S., Munday, P.L., Stillman, J.H., Reusch, T.B., (2014)

Evolution in an acidifying ocean. Trends in Ecology \& Evolution, 29(2), 117-125

58. Sundin, J., Amcoff, M., Mateos-González, F., Raby, G.D., Jutfelt, F., Clark, T.D., (2017) Long-term exposure to elevated carbon dioxide does not alter activity levels of a coral reef fish in response to predator chemical cues. Behavioral Ecology and Sociobiology 71(8), 108

59. Ward, A.J., Herbert-Read, J.E., Sumpter, D.J., Krause, J., (2011) Fast and accurate decisions through collective vigilance in fish shoals. Proceedings of the National Academy of Sciences, 108(6), 2312-2315

60. Ward, A.J., Currie, S., (2013) Shoaling fish can size-assort by chemical cues alone. Behavioral ecology and sociobiology, 67(4), 667-673

61. Warton, D.I., Lyons, M., Stoklosa, J., Ives, A.R., (2016) Three points to consider when choosing a LM or GLM test for count data. Methods in Ecology and Evolution 7, 882-890

62. Williams, C.R., Dittman, A.H., McElhany, P., Busch, D.S., Maher, M.T., Bammler, T.K., MacDonald, J.W., Gallagher, E.P., (2018) Elevated $\mathrm{CO}_{2}$ impairs olfactory- mediated neural and behavioral responses and gene expression in ocean- phase coho salmon (Oncorhynchus kisutch). Global Change Biology. 25(3), 963-977

63. Zuur, A., Ieno, E.N., Smith, G.M., (2007) Analyzing ecological data. Springer Science \& Business Media 


\section{Author Generated Postprint}

\section{Supplementary Data}

469

470 List of contents:

471 Table S1. Binomial GLM and pairwise comparisons on the sheltering time (proportion of time spent inside

472 the shelter) displayed by groups of Chromis viridis sub-adults during the pre-feeding time in the different

$473 \mathrm{CO}_{2}$ (Control and High) and Predator treatment combinations

474 Table S2. Analysis of variance showing the effects of $\mathrm{CO}_{2}$ and Predator treatments on the distance from 475 the shelter displayed by groups of Chromis viridis sub-adults.

476 Table S3. Analysis of variance showing the effects of $\mathrm{CO}_{2}$ and the Predator treatments on the average 477 distance among fish (Inter-individual distance, IID).

478 Table S4. Negative binomial GLM and pair-wise comparisons on time to emerge from the shelter (TES) 479 displayed by groups of Chromis viridis sub-adults during the feeding time in the different $\mathrm{CO}_{2}(\mathrm{Control}$ 480 and High) and Predator treatments combinations.

481 Figure S1. Schematic representation of the experimental arena 


\section{Author Generated Postprint}

Table S1 - Binomial GLM and pairwise comparisons on the sheltering time (proportion of time spent inside the shelter) displayed by groups of Chromis viridis sub-adults in the different $\mathrm{CO}_{2}$ (Control and High) and Predator treatment combinations. ns: not significant. Significant results are in bold. $\mathrm{LR}=$ log-likelihood ratio statistic, $\mathrm{DF}=$ degree of freedom; $\mathrm{p}=\mathrm{p}$ value; $\mathrm{SE}=\mathrm{Standard}$ error.

\section{Sheltering time}

\begin{tabular}{lccc}
\hline & LR & DF & p \\
Predator & 74.730 & 1 & $<\mathbf{0 . 0 0 1}$ \\
$\mathrm{CO}_{2}$ & 56.488 & 1 & $<\mathbf{0 . 0 0 1}$ \\
Predator $\mathrm{x}^{\mathrm{CO}_{2}}$ & 74.245 & 1 & $<\mathbf{0 . 0 0 1}$
\end{tabular}

Pair-wise contrasts

\begin{tabular}{|c|c|c|c|c|}
\hline & Estimate & $\mathrm{SE}$ & $\mathrm{z}$ value & $\mathrm{p}$ \\
\hline No Predator, High $\mathrm{CO}_{2}-$ Predator, High $\mathrm{CO}_{2}$ & 0.1342 & 0.10433 & 1.286 & ns \\
\hline \multirow[t]{2}{*}{ No predator, High $\mathrm{CO}_{2}-$ No predator, Control $\mathrm{CO}_{2}$} & 0.01994 & 0.10134 & 0.197 & ns \\
\hline & & & - & \\
\hline No predator, High $\mathrm{CO}_{2}-$ Predator, Control $\mathrm{CO}_{2}$ & -1.07891 & 0.10731 & 10.054 & $<0.001$ \\
\hline \multirow[t]{2}{*}{ Predator, High $\mathrm{CO}_{2}-$ No Predator, Control $\mathrm{CO}_{2}$} & -0.11425 & 0.09537 & -1.198 & ns \\
\hline & & & - & \\
\hline Predator, High $\mathrm{CO}_{2}-$ Predator, Control $\mathrm{CO}_{2}$ & -1.21311 & 0.10169 & 11.929 & $<0.001$ \\
\hline No Predator, Control $\mathrm{CO}_{2}-$ Predator, Control $\mathrm{CO}_{2}$ & -1.09886 & 0.09862 & 11.142 & $<0.001$ \\
\hline
\end{tabular}




\section{Author Generated Postprint}

Table S2 -Analysis of variance showing the effects of $\mathrm{CO}_{2}$ and Predator treatments on the distance from the shelter displayed by groups of Chromis viridis sub-adults. Significant effects (p-value) were calculated by sequential $\mathrm{F}$ test comparing each model with a null model basing on resampling iterations ( $\mathrm{n}=999)$. ns: not significant. Significant results are in bold. $D F=$ degree of freedom; $p=p$ value; Fstat $=F$ statistic.

\section{Distance from shelter}

Fstat DF $\quad$ p (Resampling)

NULL

Predator 5.708

1

$\mathbf{0 . 0 3}$

$\mathrm{CO}_{2}$

5.439

1

0.028

Predator x $\mathrm{CO}_{2}$

0.249

1

nS

486

487 


\section{Author Generated Postprint}

Table S3 - Analysis of variance showing the effects of $\mathrm{CO}_{2}$ and the Predator treatments on the average distance among fish (Inter-individual distance, IID). Significant effects ( $p$-value) were calculated by sequential test $\mathrm{F}$ test comparing each model with a null model basing on resampling iterations (n=999). ns: not significant. Significant results are in bold. $\mathrm{DF}=$ degree of freedom; $\mathrm{p}=\mathrm{p}$ value; Fstat $=\mathrm{F}$ statistic.

\section{Inter-Individual Distance}

Fstat DF p (Resampling)

NULL

Predator

6.305

1

0.016

$\mathrm{CO}_{2}$

0.519

1

ns

Predator x $\mathrm{CO}_{2}$

0.486

1

ns 


\section{Author Generated Postprint}

Table S4 - Negative binomial GLM and pair-wise comparisons on time to emerge from the shelter (TES) displayed by groups of Chromis viridis sub-adults during the feeding time in the different $\mathrm{CO}_{2}$ (Control and High) and Predator treatments combinations. ns: not significant. Significant results are in bold. LR= loglikelihood ratio statistic, $\mathrm{DF}=$ degree of freedom; $\mathrm{p}=\mathrm{p}$ value; $\mathrm{SE}=\mathrm{Standard}$ error.

\section{Time to emerge from shelter}

LR DF $p$

NULL

Predator

8.48

1

0.0035

$\mathrm{CO}_{2}$

8.58

1

0.0033

Predator x $\mathrm{CO}_{2}$

6.70

1

0.0096

Pair-wise contrasts

\begin{tabular}{|c|c|c|c|c|}
\hline & Estimate & S.E. & $\mathrm{z}$ value & $\mathrm{p}$ \\
\hline High $\mathrm{CO}_{2}$, No Pred - Control $\mathrm{CO}_{2}$, No Pred & -0.10821 & 0.40871 & -0.265 & ns \\
\hline High $\mathrm{CO}_{2}$, No Pred $-\mathrm{High} \mathrm{CO}_{2}$, Pred & -0.04652 & 0.4171 & -0.112 & ns \\
\hline High $\mathrm{CO}_{2}$, No Pred - Control $\mathrm{CO}_{2}$, Pred & -1.59505 & 0.42740 & -3.732 & $<0.001$ \\
\hline Control $\mathrm{CO}_{2}$, No Pred - High $\mathrm{CO}_{2}$, Pred & 0.06169 & 0.36365 & 0.170 & ns \\
\hline Control $\mathrm{CO}_{2}$, No Pred - Control $\mathrm{CO}_{2}$, Pred & -1.48684 & 0.37537 & -3.961 & $<0.001$ \\
\hline High $\mathrm{CO}_{2}$, Pred - Control $\mathrm{CO}_{2}$, Pred & -1.54853 & 0.38453 & -4.027 & $<0.001$ \\
\hline
\end{tabular}

492
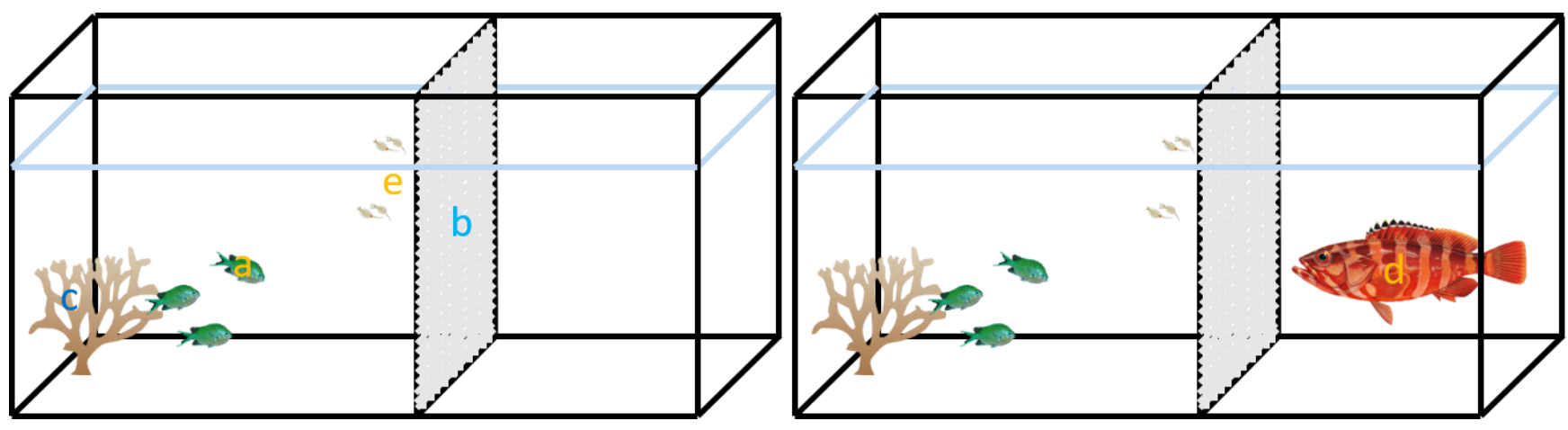


\section{Author Generated Postprint}

494 Fig. S1 - Schematic representation of the experimental arenas used for the assessments of C.viridis group 495 behaviour without predatory threat (left) or in presence of the predator (right) after a 5-day exposure to

496 Control or High $\mathrm{CO}_{2}$ concentrations. a): C. viridis sub-adult group; b): rigid mesh (1 mm mesh size); c): 497 coral shelter; d): predator; e) food stimulus (Artemia sp. adults). 